DOI: $10.12957 /$ teias.\%Y.50913

\title{
DESENVOLVIMENTO PROFISSIONAL DOCENTE E A FORMAÇÃO DO HOMO CREARE EXPERIMENTALIS
}

\author{
Carlos José Trindade da Rocha
}

\section{Resumo}

Neste artigo, objetiva-se demonstrar um processo viável de formação do sujeito criativo investigativo, no ensino e aprendizagem de ciências, sob a égide do desenvolvimento profissional docente. Para isso, implementaram-se fases de criatividade com uso de Sequência de Ensino Investigativa (SEI) na experimentação investigativa. A metodologia foi norteada pela abordagem qualitativa, orientada por características que se mantêm ligadas a ideias e ações sociais de tendência emancipatória, ao mesmo tempo em que fundamenta e instrumentaliza a educação científica. As inferências de resultados apontam para demandas de formação ao homo creare experimentalis, ou seja, aquele sujeito que desenvolve processos de imaginação, com criatividade e autonomia, envolvendo a resolução de problemas propostos, em contornos de atividades investigativas. Além disso, nesta proposição formativa, possibilita-se exploração de ideias e previsões, elaborando planos de ações e experimentando o que se planeja, comunicando e socializando resultados com autonomia, permitindo, assim, atos criativos à ação de ensino e aprendizagem de professores e alunos.

Palavras-chave: formação de professores; ensino por investigação; criatividade; homo creare experimentalis.

\section{PROFESSIONAL TEACHING DEVELOPMENT AND THE FORMATION OF HOMO CREARE EXPERIMENTALIS}

\section{Abstract}

This article aims to demonstrate a viable process of training the creative investigative subject in science teaching and learning, on the aegis of professional teacher development. For this, phases of creativity were implemented using the Investigative Teaching Sequence (ITS) in investigative experimentation. The mythology was guided by the qualitative approach, guided by characteristics that remains linked to social ideas and actions of an emancipatory tendency, at the same time that it bases and instrumentalizes scientific education. The inferences of results point to training demands for homo creare experimentalis, that is, that subject who develops imagination processes, with creativity and autonomy, involving the resolution of proposed problems, in the contours of investigative activities. In addition, in this formative proposition it is possible to explore ideas and forecasts, elaborating action plans and experimenting with what is planned, communicating and socializing results with autonomy, allowing creative acts to the teaching and learning acts of teachers and students.

Keywords: teacher training; inquiry; creativity; homo creare experimentalis.

\section{DESARROLLO DOCENTE PROFESIONAL Y LA FORMACIÓN DE HOMO CREARE EXPERIMENTALIS}

Resumen

Este artículo tiene como objetivo demostrar un proceso viable de formación de la asignatura de investigación creativa en la enseñanza y el aprendizaje de las ciencias, bajo los auspicios del desarrollo profesional de los docentes. Para esto, se implementaron fases de creatividad utilizando la Secuencia de Enseñanza de Investigación (SEI) en la experimentación investigativa. La metodología se guió por el 
DOI: $10.12957 /$ teias.\%Y.50913

enfoque cualitativo, guiado por características que permanecen vinculadas a las ideas y acciones sociales de una tendencia emancipadora, al mismo tiempo que fundamenta e instrumentaliza la educación científica. Las inferencias de resultados apuntan a demandas de capacitación para el homo creare experimentalis, es decir, aquel sujeto que desarrolla procesos de imaginación, con creatividad y autonomía, que involucran la resolución de problemas propuestos, en los contornos de las actividades investigativo. Además, en esta propuesta formativa es posible explorar ideas y pronósticos, elaborar planes de acción y experimentar con lo planificado, comunicar y socializar resultados con autonomía, permitiendo actos creativos para los actos de enseñanza y aprendizaje de docentes y estudiantes.

Palabras clave: formación del profesorado, enseñanza docente; creatividad; homo creare experimentalis.

\section{INTRODUÇÃO}

A formação do homo creare experimentalis significa a formação do indivíduo que atua criativamente, amparado por dinâmicas investigativas, ampliando seu repertório conceitual, procedimental e atitudinal, principalmente, na experimentação investigativa realizada, a partir de diferentes materiais e espaços, muito além dos laboratórios científicos.

Nesta perspectiva, aciona-se um conjunto de práticas e atos criativos, para proporcionar um aprender contextualizado e, assim, produzir o sujeito criativo investigativo. O ensino por investigação, dentro da tendência da experimentação investigativa, tema centralizador deste artigo, foi escolhido em função de uma proposição explorada em um estágio de pósdoutoramento, que, uma vez compreendido, pode ser adaptado para todas as disciplinas na atuação profissional docente.

Esta proposição articula-se com as ideias de metodologias ativas, em cooperação entre professores de escolas públicas, alunos de pós-graduação, licenciaturas ou projetos de extensão desenvolvidos no âmbito de Pós-Graduação em Ensino de Ciências e Matemática, vinculado a uma universidade federal do Amazonas, contribuindo de forma a permitir ampliação do lastro de pesquisa deste programa, tanto para o desenvolvimento de pesquisas acerca da formação de professores em espaços formais e não formais de educação científica, como para ensino e aprendizagem.

Nessa perspectiva criativa experimental, aciona-se um conjunto de práticas e de técnicas para proporcionar um aprendizado contextualizado e, assim, produzir o homo creare experimentalis, ou seja, o sujeito investigativo. Conforme Rocha e Farias (2020), podem-se encontrar demandas ao sujeito investigativo, aquele sujeito que desenvolve processos de imaginação, com criatividade e autonomia, envolvendo a resolução de problemas propostos, fazendo uso da pesquisa, ensino ou extensão. Além de explorar ideias e previsões, elaborando, dessa forma, possíveis planos de ações e experimentando o planejado, comunicando e socializando os resultados.

A discussão a respeito da formação dos processos criativos afirma que toda a espécie humana tem a capacidade de criação. O cérebro humano é dotado, do ponto de vista biológico, do poder de criar (CRUZ-GUZMÁN, GARCÍA-CARMONA, CRIADO, 2011). O ato de criar necessita do desenvolvimento da habilidade mental de unificar imagens diferentes em novos contextos e combinações para se pensar e produzir alterações na realidade (SIRY, KREMER, 2011). 
Dessa forma, destacam-se possibilidades de transformação e oportunidades para o desenvolvimento profissional docente (DPD), contribuindo para melhorar a prática remetida às abordagens de metodologias ativas, pois permite o contínuo de formação, operando, assim, sobre as pessoas, não sobre os programas (ROCHA, 2019).

Neste contexto, propomo-nos a responder à seguinte questão de pesquisa: De que forma, pode-se possibilitar a formação do sujeito criativo investigativo com aspectos de protagonismo, reflexões e intervenções para o desenvolvimento profissional docente?

A formação e a execução nesta proposição devem ocorrer de maneira interativa e colaborativa, a fim de tentar analisar o entendimento da complexa dinâmica, envolvendo os processos de formação, as metodologias ativas em perspectiva do sujeito investigativo, que têm motivado o desenvolvimento de atos criativos relacionadas ao discurso de formação de professores, buscando melhorar seu impacto na condução de desenvolvimento formativo para o inquiry na região do Amazonas.

Assim, este trabalho concentra-se em demonstrar possibilidades no processo de formação do sujeito criativo investigativo e sua importância, por meio da experimentação investigativa com uso de Sequência de Ensino Investigativa (SEI) no contexto amazônico de educação científica.

\section{DESENVOLVIMENTO PROFISSIONAL DOCENTE}

Este trabalho busca participar de um movimento que caracteriza o desenvolvimento profissional, por meio de atitudes investigativas permanentes de aprendizagem. Desta maneira, a discussão a respeito da formação dos processos criativos enfatiza que toda a espécie humana tem a capacidade de criação (ARCE, SILVA, VAROTTO, 2011).

Assim, os autores concebem que o cérebro humano é dotado, do ponto de vista biológico, do poder de criar. $\mathrm{O}$ ato de criar necessita do desenvolvimento da habilidade mental de unificar imagens diferentes em novos contextos e combinações, para se pensar e produzir alterações na realidade (ARCE, SILVA, VAROTTO, 2011).

Neste contexto, a expressão desenvolvimento profissional docente (DPD) pode corresponder a outros termos que são utilizados com frequência, tais como: formação permanente, contínua, em serviço, desenvolvimento de recursos humanos, aprendizagem ao longo da vida, experiência em exercício, cursos de reciclagem ou de capacitação, entre outros (VAILLANT, MARCELO, 2012).

Todavia, neste trabalho, não discorreremos sobre outros entendimentos acerca deste campo, com articulações de aspectos divergentes ou convergentes. Independente dos termos e concepções possíveis, em nosso entendimento, todas comportam a proposta de SEI.

Aqui defendemos que a noção de desenvolvimento profissional é a que melhor se adapta à concepção docente como profissional do ensino. Uma vez que o conceito de desenvolvimento tem uma conotação de evolução e continuidade, que supera a tradicional justaposição entre formação inicial e aperfeiçoamento dos docentes (ROCHA, 2019). O conceito de DPD “[...] tem a ver com 
a aprendizagem; remete ao trabalho; trata de um trajeto; inclui oportunidades ilimitadas para melhorar a prática; relaciona-se com a formação dos docentes; e opera sobre as pessoas, não sobre os programas" (VAILLANT, MARCELO, 2012, p. 169).

Há, portanto, a necessidade de DPD que propicie atualização, renovação de conhecimento, habilidades e capacidades aos professores; essa deve ser pauta de prioridade nas políticas educacionais, especialmente nos países em desenvolvimento (VAILLANT; MARCELO, 2012; MIZUKAMI, 2010). Entender o conceito de DPD é fundamental para desenvolver oportunidades de aprendizagem que promovam nos educadores capacidades criativas e investigativas que lhes permitam melhorar suas práticas.

Por um lado, temos a concepção de que os sujeitos produzem cultura, e, portanto, já nascem dotados de talentos e aptidões que se desenvolverão por meio de um processo educativo calcado apenas em seus interesses, sendo o professor um guia/ajudante que deve trabalhar apenas com as subjetividades, pois se tem a prerrogativa de que o ensino destrói o ser criativo (ARCE; SILVA; VAROTTO, 2011).

De outro lado, explicita-se claramente a necessidade de atividades intencional do ensino, da transmissão dos conhecimentos historicamente acumulados, como essencial para que o sujeito comece a se constituir, enquanto sujeito investigativo capaz de intervir, modificar e explorar criativamente o mundo em que se encontra.

Partindo da premissa de que o sujeito investigativo é influenciado por um conjunto de fatores, a aprendizagem pode ser incluída como um indicador de qualidade, possuindo elementos básicos para explicar o desenvolvimento profissional (figura 1) em perspectiva do ensino por investigação, que são: o conteúdo, o processo e o contexto.

Figura 1: O DPD e o aprendizado em perspectiva do sujeito investigativo

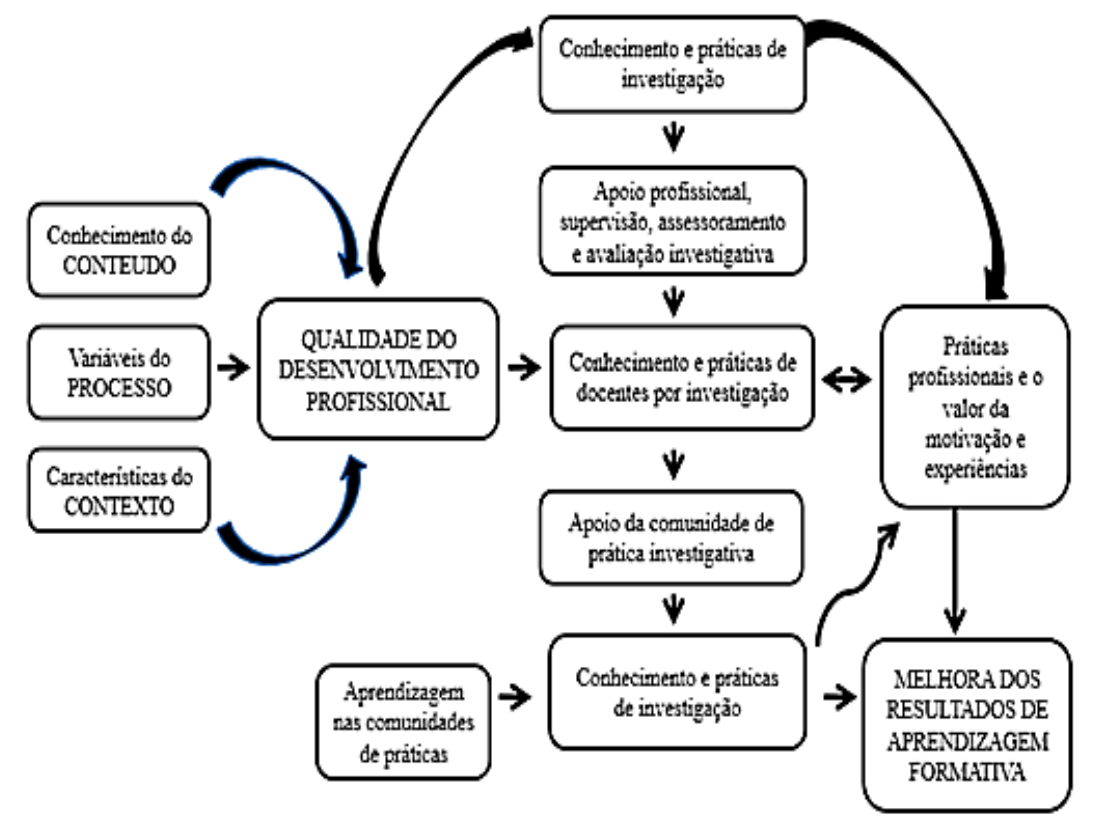

Fonte: Rocha (2019) 
DOI: $10.12957 /$ teias. $\%$ Y.50913

As concepções que se derivam da estrutura proposta por Rocha (2019) estão em consonância com algumas pesquisas da área que tratam a questão do DPD (FIORENTINI, CRECCI, 2013; GONÇALVES, 2013; TARDIF, 2013; GATTI, 2010; MIZUKAMI, 2010) e a aprendizagem dos estudantes, o que implica a organização, o sistema ou a cultura em que o desenvolvimento profissional se desenvolve.

Conforme a figura 1, quanto à qualidade do DPD, a característica do conteúdo refere-se ao "o que" e tem a ver com o conhecimento, as habilidades, a compreensão de uma disciplina, é o conhecimento sobre a forma como se aprende. O processo refere-se ao "como" e vincula-se não somente às atividades que se desenvolvem, mas também à forma de planejá-las, desenvolvê-las e dar-lhes continuidade. As características do contexto remetem-se ao "quem, quando, onde e porque" do desenvolvimento profissional. Essas variáveis implicam a organização, o sistema ou a cultura na qual o DPD é desenvolvido.

O conteúdo, os processos e o contexto das atividades de DPD estão articulados na busca dos significados que os sujeitos constroem com suas experiências, mediadas na diversidade de contextos em perspectiva investigativa. A ideia dessa estrutura concebe que, em primeiro lugar, ainda que as relações entre o desenvolvimento profissional e seu aprendizado sejam complexas e multifatoriais, não são malogradas nem caóticas.

Nessa perspectiva, deve-se levar em conta a qualidade do conhecimento e as práticas dos docentes como fatores que influenciam e determinam essa aprendizagem. Se uma atividade de formação "[...] não chega a melhorar o conhecimento e as práticas docentes, pode ser que o desenvolvimento tenha sido com qualidade, mas sua eficácia será baixa" (VAILLANT, MARCELO, 2012, p. 178).

Alguns autores (BASSOLI, LOPES, 2015; ROSSI, HUNGER, 2012; FORSTER, et al., 2011; MARCELO GARCÍA, VAILLANT, 2009) buscaram estabelecer a expertise entre docentes e compreender o processo de transformação de um especialista e o que caracteriza estes profissionais. Esses autores referem-se ao docente especialista, não somente como aquele professor com, ao menos, alguma experiência, mas, sobretudo a uma pessoa com um elevado nível de conhecimento e destreza.

Para Vaillant e Marcelo (2012), os sujeitos especialistas em qualquer das áreas têm em comum as seguintes características: a) a complexidade das destrezas, ou seja, realiza suas ações apoiando-se em uma estrutura diferente e mais complexa que a do principiante, exercendo um controle voluntário e estratégico sobre as partes do processo, que se desenvolve mais automaticamente no caso do principiante; b) assinalam a estrutura do conhecimento; e c) representação do problema.

Os sujeitos especialistas entendem a estrutura abstrata do problema e utilizam uma variedade de tipos de problemas armazenados em sua memória. Percebe-se que ao especialista cabe uma estrutura de conhecimento profunda e multinivelada, com muitas conexões inter e intraniveladas. Em consequência, o conhecimento especializado consiste em muito mais que uma lista de feitos desconectados acerca de determinada disciplina. Pelo contrário, seu conhecimento está conectado e organizado em torno de ideias importantes sobre suas disciplinas. Essa 
organização do conhecimento permite "[...] identificar quando, por que e como" utilizar em uma situação particular, os conhecimentos que possuem (VAILLANT, MARCELO, 2012, p. 129).

Os autores propõem uma ideia de transformação em docente (figura 2) que é pertinente para entender o processo de inserção profissional e, como consequência, programar ações formativas investigativas para o processo de transformação docente.

Figura 2: $\mathrm{O}$ processo de transformação em docente

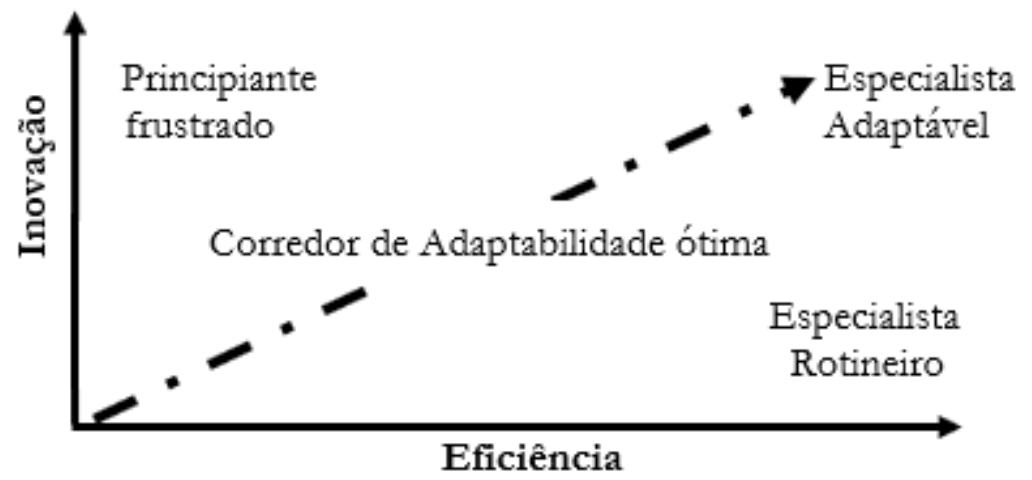

Fonte: Vaillant e Marcelo (2012).

Vaillant e Marcelo (2012) propõem uma diferença entre um especialista rotineiro e o especialista adaptativo. Ambos são especialistas que continuam aprendendo ao longo de suas vidas. Porém, há a necessidade de se estabelecer distinções entre eles. O especialista rotineiro desenvolve um conjunto de competências que aplica ao longo de sua vida, cada vez com maior eficiência. Pelo contrário, o "[...] especialista adaptativo tem maior disposição a mudar suas competências para aprofundá-las e ampliá-las continuamente” (VAILLANT, MARCELO, 2012, p. 129).

Outro aspecto são duas dimensões relevantes no processo de transformar-se em um docente especializado: inovação e eficiência. A adaptabilidade em uma só dimensão poderá não apoiar um movimento adaptativo. As pessoas se beneficiam mais de oportunidades de aprendizagem, que fazem parte de um balanço adequado entre as duas dimensões dentro do corredor de (trans)formação. Neste sentido, muitos programas estão adotando uma ideia de expertise adaptativa como modelo de desenvolvimento profissional docente (VAILLANT, MARCELO, 2012).

Expertise adaptativa é uma característica de inserção à docência, evidenciada pela formação humanística, que tiveram relativo êxito em países desenvolvidos como Inglaterra, França, Suíça, Japão, Estados Unidos, entre outros. A preparação supervisionada de módulos de inserção à docência, o acompanhamento de um mentor ou tutor especialista, a participação dos docentes novatos em seminários, a comunicação constante com diretores de estabelecimento de ensino e o tempo dedicado a planejar aulas e ao trabalho colaborativo (VAILLANT, MARCELO, 2012) possibilitam a eficácia de formação, que se destaca pela destreza e competência na execução de um trabalho considerando a experiência e prática com base em conhecimentos contínuos.

\section{FORMAÇÃO DO SUJEITO CRIATIVO INVESTIGATIVO}

Inspirado principalmente na proposta de qualidade de desenvolvimento profissional docente (ROCHA, 2019) e de aspectos de criatividade (PILETTI, 1997), construímos uma 
proposição de instrumento de análise, visando propiciar um maior detalhamento das ações em atividades do ensino de ciências e matemática, na busca por uma construção mais refinada e, portanto, possibilitando uma compreensão de diferentes aspectos relacionados à interação de formação do sujeito investigativo.

Tendo em vista a relevância do ensino investigativo, propomos relações formativas (figura 3), enfatizando proposições de atividades no ensino de ciências e matemática, associadas às concepções de Sequência de Ensino Investigativa (CARVALHO, 2013) e Piletti (1997), que concebe a criatividade em fases, que em nosso entendimento, permite dinamizar o desenvolvimento do creare experimentalis no contexto analisado.

Figura 3: Relações formativas do sujeito criativo investigativo

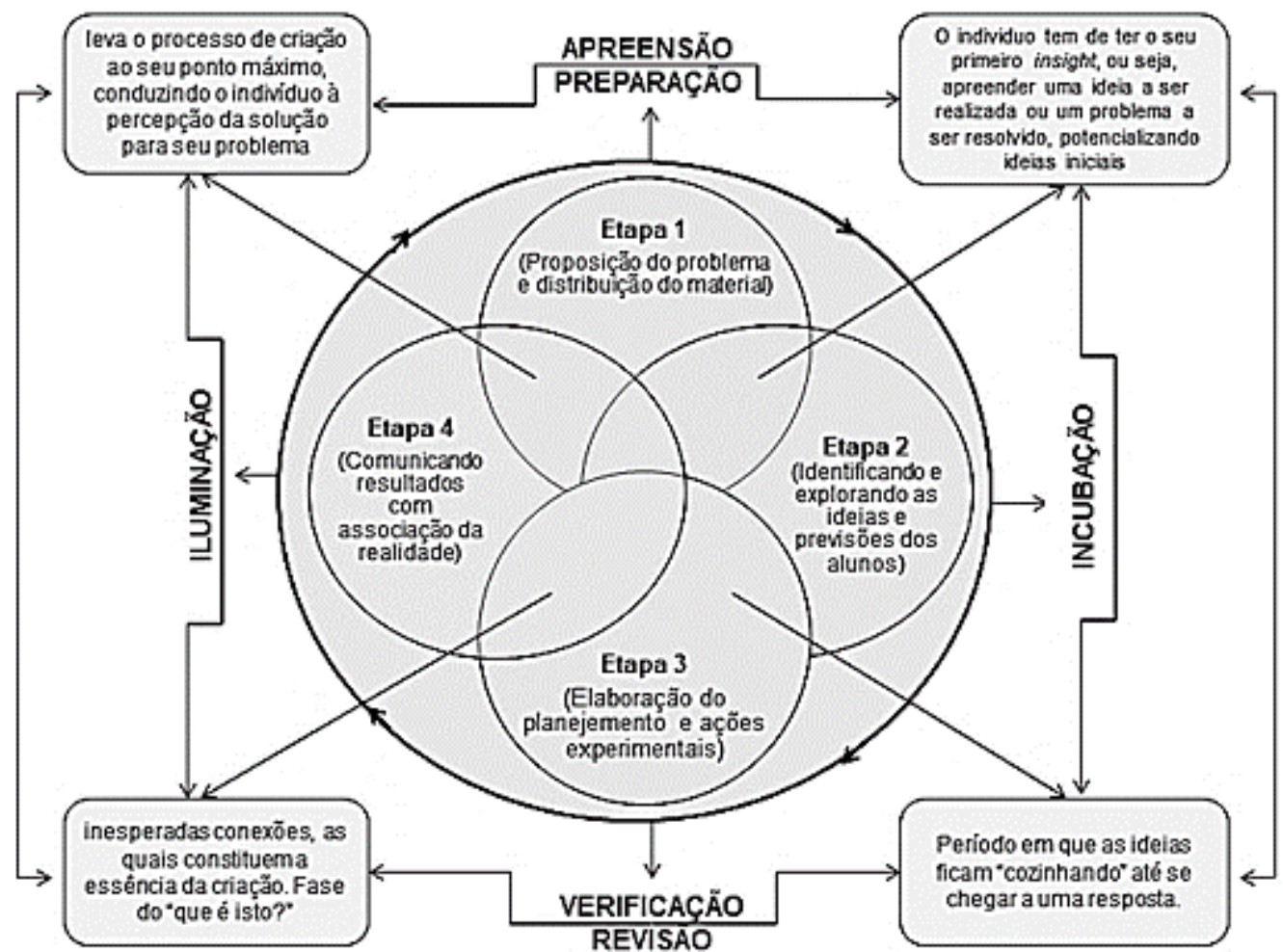

Fonte: O autor com base em Carvalho (2013) e Piletti 1997).

Essas relações consideram a triangulação da forma proposta, contemplando os processos de criação considerados ao sujeito investigativo, e que se traduzem pela capacidade de reter imagens extraídas das experiências sociais anteriores para combiná-las com elementos novos.

Piletti (1997) afirma que a criatividade acontece gradativamente em fases ou etapas reconhecíveis. Para ele, o processo criativo desenvolve-se durante um período, e este pode ser analisado como sendo composto de vários estágios da atividade criativa. $\mathrm{O}$ autor propõe o desenvolvimento da criatividade em cinco fases: apreensão, preparação, incubação, verificação e iluminação.

A primeira fase é da apreensão, caracterizada por uma demorada preparação consciente, seguida por intervalos de atividade não consciente. O indivíduo tem de ter o seu primeiro insight, 
ou seja, apreender uma ideia a ser realizada ou um problema a ser resolvido. Até o momento da apreensão, o criador não teve inspiração, mas apenas a noção de algo a fazer.

$\mathrm{Na}$ sequência, vem a fase da preparação, que é constituída pela investigação das potencialidades da ideia inicial. O indivíduo lê, anota, discute, indaga, coleciona. Nesta fase, a investigação abre possíveis soluções, ponderando a viabilidade de cada proposta. A preparação inclui também o meio criador. A criação requer técnica, que pode ser bruta ou refinada, conforme a natureza do meio e da atividade.

A outra fase é a incubação, caracterizada pelo trabalho do inconsciente que, sem limites e desimpedimentos pelo intelecto literal, faz as inesperadas conexões, as quais constituem a essência da criação. $\mathrm{Na}$ fase de verificação ou a revisão, o criador precisa distinguir, na sua produção, o que é válido, pois a fase de iluminação é falível. Embora a apresentação das fases da atividade criativa seja tão evidente, não há como separá-las. Seguindo a ordem, aparece a fase da iluminação que leva o processo de criação ao seu ponto máximo, pois, de repente, o criador percebe a solução para seu problema, o conceito que enfoca todos os fatos ou o pensamento que completa as ideias trabalhadas, conduzindo o indivíduo à percepção da solução para seu problema.

Ressalta-se que há fortes evidências do quanto é necessário avançar, tanto nos cursos de formação inicial, quanto nos cursos de formação continuada, em relação ao entrelaçamento entre formação e a dimensão do ensino, ou seja, em uma situação de equilíbrio entre a dimensão didática, pedagógica e epistemológica. De nosso ponto de vista, tal equilíbrio só será possível se, nos cursos de formação, forem desenvolvidos processos que levem o sujeito a adotar uma relação investigativa com os saberes e não apenas a acumulação de conhecimentos conceituais.

Nesta perspectiva, na etapa 1 (Proposição de problema e distribuição de materiais) da proposição da SEI em atividades propostas, associa-se à fase de apreensão, considerando a novidade, o que Piletti (1997) concebe como a primeira característica da criatividade. Uma ideia, um comportamento ou um objeto são criativos na medida em que são novos. Essa novidade pode referir-se tanto ao sujeito que cria, quanto ao conhecimento existente naquele momento.

Dependendo da atividade investigativa desenvolvida, instiga-se a curiosidade dos sujeitos e, em um ambiente lúdico e estimulante, eles começam a fazer várias tentativas para soluções de problemas. Nessa apreensão, o momento criativo não acontece de imediato. $\mathrm{O}$ ato criador é resultado dessas tentativas, do surgimento de uma ideia para resolução do problema (ROCHA; MALHEIRO, 2018; 2017).

Em meio a dúvidas, impasses e incertezas, o sujeito creare experimentalis é aí requisitado como uma estratégia do discurso científico. Como é por meio da experimentação que se traz a verdade, demanda-se que o sujeito investigativo, quando está em dúvida ou suspeita, opere atos criativos, para que sua verdade logo surja. Assim, a verdade científica é vivenciada pelos sujeitos por meio de suas produções internas acerca de seus métodos e procedimentos. A verdade científica produzida, portanto, quando se revela, registra, testa e teoriza sobre um fenômeno experimentado (CARDOSO, PARAÍSO, 2015). 
Neste contexto, Rocha e Malheiro (2017) consideram que a interrogação é outra condição da atividade criativa. Corroborando com Piletti, (1997) no pensamento criador, é tão importante fazer e refazer perguntas quanto respondê-las. O papel do professor nessa etapa é verificar se os sujeitos entenderam o problema proposto, deixando-lhes trabalhar (CORTELLA, CASADEI, 2009).

Além disso, também há a parte afetiva, pois é muito mais fácil propor suas ideias a um colega, que ao professor. E, como o erro nessa etapa é importante para separar as variáveis que interferem daquelas que não interferem na resolução do problema, “[...] os sujeitos precisam errar, isto é, propor coisas que pensam testá-las e verificar que não funcionam” (CARVALHO, 2013, p. 12), ou seja, experimentar sem medo de errar (SILVA, MACHADO, TUNES, 2010).

Com base nesses pressupostos e da manipulação do material didático disponibilizado, é que os sujeitos na etapa 2 vão levantar hipóteses/previsões e experimentá-las para resolver o problema. Para que ocorra uma verdadeira criação, a receptividade é a primeira das condições, pois as ideias criadoras não podem ser forçadas, e se não há receptividade, as ideias não surgem.

A fase de preparação consiste num trabalho sistemático de constituição de informações relacionadas à ideia original e convenientemente organizadas, para que possam ser utilizadas quando necessário. Tal condição nutre a imaginação e fortalece o ato criador, pois oferece uma série de novas abordagens em relação ao problema, evidencia novos caminhos para a sua solução e ajuda o sujeito da atividade criativa a pensar mais profundamente e de modo mais global a respeito do ato criador (PILETTTI, 1997).

Além da apreensão e preparação, a receptividade, dedicação e o desprendimento também são condições essenciais para o desenvolvimento da criatividade. Na fase de incubação, o trabalho é inconsciente. Os períodos de preparação e incubação podem alternar-se no mesmo ato criador. Como já mencionado, a incubação consiste naquela fase em que a pessoa deixa de lado as informações constituídas e dedica-se a outras atividades, parecendo esquecer seu trabalho. Nessa fase, o inconsciente realiza associações, organiza ideias, trabalha sobre as questões levantadas, a partir das informações colhidas (KNELLER, 1999).

$\mathrm{Na}$ elaboração do planejamento e ações experimentais da proposição da SEI (etapa 3), manifestam-se as questões levantadas. Nesta etapa, o sujeito envolve-se profundamente em seu trabalho, para reunir a energia necessária à concentração que a atividade criativa exige. Ao mesmo tempo, é preciso cuidado quando o sujeito focaliza em demasia seu trabalho, podendo limitar seu pensamento e prejudicar a criatividade. Desta forma, é necessário desprendimento, para que se consiga ver o processo como um todo, permitindo, assim, outras formas de leitura e observação da atividade criativa (PILETTTI, 1997).

Ainda nesta fase, a imaginação e o julgamento são igualmente condições da atividade criativa. A imaginação produz ideias, porém não as comunica; já o julgamento comunica as ideias, mas não as produz. A criatividade só ocorrerá se houver cooperação entre a imaginação e julgamento, uma vez que a atividade criativa é, ao mesmo tempo, produção e comunicação (PILETTI, 1997). 
DOI: $10.12957 /$ teias. $\%$ Y.50913

Esta vinculação é representada na etapa 4 da SEI - comunicação dos resultados, associandoos com a realidade. Pode-se considerar o momento culminante do processo criativo, pois é nele que aparece a solução do problema. Embora os sujeitos tenham limites muito claros, no processo investigativo, não se espera atos criativos extraordinários. O problema não é estudar o fenômeno de maneira neutra, e sim de "[...] criar condições segundo as quais esse fenômeno dará testemunho" (STENGERS, 1990, p. 84). O desafio está em respeitar os limites dos sujeitos, para que possam aprender ciência com alegria e prazer.

Nesse julgamento se dá a verificação, na qual o criador tenta dar forma final à inspiração que teve. Pode conseguir fazê-lo ou não. Caso não consiga, convém abandonar a primeira apreensão e procurar uma nova ideia, recomeçando o processo. Algumas vezes, após o momento de iluminação, leva-se tempo para elaborar e rever previsões ou hipóteses (PILETTI, 1997).

Sustenta-se que os sujeitos criativos investigativos possuem capacidades inatas para construir representações sobre a realidade natural, podem exercer seu pensamento sobre as coisas e, à medida que expõem e socializam suas dúvidas e descobertas para o professor e seus colegas, podem rever suas explicações criativas sobre o que ocorre em fenômenos naturais e elaborar compreensões dentro de seus graus cognitivos.

Kneller (1999) considera que, no processo criativo, há um impulso para criar. Segue-se a este um período, em que o criador recolhe material e investiga diferentes métodos de trabalhá-lo. Vem, a seguir, um tempo de incubaşão, no qual a obra criadora procede inconscientemente. Então, surge o "[...] momento da iluminação, e o inconsciente anuncia, de súbito, os resultados de seu trabalho" (KNELLER, 1999, p. 73).

O processo investigativo distribui encantamentos sobre as ciências. Se tais sujeitos se posicionam como creare experimentalis, é porque, na SEI proposta, pode-se produzir um desejo pela empiria, ao se propor a solução de um problema, graduando o desafio de modo que as dificuldades possuam um grau compatível com a fase criativa do sujeito, o que significa que não podem ser tão fáceis que não motivem o desenvolvimento de ações criativas, nem tão difíceis a ponto de levar o sujeito a desistir (ARCE; SILVA; VAROTTO, 2011).

Com o discurso de metodologias ativas, na educação para a ciência, “[...] o sujeito pode ser o agente ativo graças ao qual a verdade emerge” (FOUCAULT, 2010, p. 65). O sujeito estará a “[...] aprender, conhecer e compreender a ação humana e os conhecimentos que dela frutificarem e acumularem-se em práticas e objetos, na vida e no mundo" (ARCE, SILVA, VAROTTO, 2011, p. 61).

Essa abordagem didática pode estar presente em espaços não formais de educação científica, desenvolvendo formação e desenvolvimento profissional docente (CASCAIS, TERÁN, 2014; MARANDINO, SELLES, FERREIRA, 2009).

\section{CONSIDERAÇÕES FINAIS}


DOI: $10.12957 /$ teias. $\%$ Y.50913

As ações criativas de professores permitem o desenvolvimento profissional docente, desenvolvendo conhecimento científico com expertise adaptativa por meio da concepção do inquiry (ensino por investigação). O sujeito criativo investigativo, ou seja, o bomo creare experimentalis é aquele que atua criativamente, amparada por distintas dinâmicas ampliando seu repertório conceitual, procedimental e atitudinal criando ações científicas com alegria e prazer.

Desta forma, a criatividade e a autonomia, com uso de Sequência de Ensino Investigativa proposta, possibilitam a resoluções de problemas, fazendo uso de metodologias ativas de aprendizagem como experimentação investigativa. Portanto, é uma forma de consolidar o inquiry na formação e atos de ensino de professores para educação científica.

Proporciona um ambiente alternativo de ensino, em prol da popularização da ciência, da iniciação científica e da formação inicial e continuada de professores. Nesse contexto, a formação do sujeito criativo investigativo é uma das estratégias que ajuda a desenvolver nas crianças processos criativos, percepções de fenômenos e compreensão de conceitos e fenômenos observáveis.

É nessa clareza de que as atividades e seus resultados envolvem concepções e ideias criadas, desenvolvidas por sujeitos que se identificam com a ciência, que se posicionam nesse discurso e passam a agir de acordo com suas verdades. Sujeitos investigativos da criatividade, ou sujeitos creare experimentalis, no entanto, não são cientistas ou escolares científicos.

Este sujeito investigativo trata-se de um conhecer, apreender e compreender o mundo real. Assim, o conhecimento científico é o resultado do desenvolvimento de criatividades, conceitos e teorias para se conhecer, compreender e apreender o mundo e, ao ensinar-se ciências, não se pode prescindir dele. Vê-se, portanto, que a criatividade investigativa não restringe o seu alcance aos laboratórios científicos.

Portanto, acreditamos que nossa proposição pode contribuir para o desenvolvimento de capacidades inovadoras e eficientes na formação de especialistas adaptáveis para atuação no ensino superior e na educação básica e para o desenvolvimento de pesquisas na área de ensino por investigação alinhadas com as necessidades contemporâneas.

\section{REFERÊNCIAS}

ARCE, Alessandra; SILVA, Débora; VAROTTO, Michele. Ensinando ciências na educação infantil. Campinas, SP. Editora Alinea. 2011.

BASSOLI, Fernanda; LOPES, José Guilherme. Formação Continuada de Professores de Ciências em um Grupo Colaborativo: Construindo caminhos. Anais... X ENPEC Águas de Lindóia, SP. nov. 2015. Disponível em: http://www.abrapecnet.org.br/enpec/xenpec/anais2015/listaresumos.htm Acesso em 12 nov. 2020.

CARDOSO, Lívia de Rezende; PARAÍSO, Marlucy Alves. Dispositivo da experimentação e produção do sujeito homo experimentalis em um currículo de ciências. Educação em Revista, v. 31, 2015, p. 299-320.

CARVALHO, Ana Maria Pessoa. O ensino de ciências e a proposição de sequências de ensino investigativas. In: Carvalho, Ana Maria Pessoa (org.) Ensino de Ciências por Investigação: Condições para implementação em sala de aula - São Paulo: Cengage Learning, p. 1-20, 2013.

CASCAIS, Maria das Graças Alves; TERÁN, Augusto Fachín. Educação formal, informal e não formal na educação em ciências. In: Ciência em tela. v. 7, n. 2, 2014. 
CORTELLA, Mário Sérgio; CASADEI, S. R. O que épergunta? 2 ed. São Paulo: Cortez, 2009.

CRUZ-GUZMÁN, Marta Alcalá; GARCÍA-CARMONA, Antonio; CRIADO, Ana García-legaz. Aprendiendo sobre los cambios de estado en educación infantile mediante secuencias de preguntapredicción-comprobación experimental. Enseñanza de las ciências, 35, 3, 2011, p. 175-193.

FIORENTINI, Dario; CRECCI, Vanessa Moreira de. Desenvolvimento Profissional Docente: Um Termo Guarda-Chuva ou um novo sentido à formação? Form. Doc. Belo Horizonte, v. 05, n. 08, p. 11-23, jan./jun. 2013.

FORSTER, Maria Margarete dos Santos; VEIT, Carina Maria Veit; ANTICH, Andréia Veridiana; REIS, Marelise de Fátima Griebeler. A formação continuada de professores no espaço escolar: impactos na prática docente. Rev. Diálogo Educ., Curitiba, v. 11, n. 33, p. 497-514. 2011.

FOUCAULT, Michel. Vigiar e Punir: nascimento da prisão. Petrópolis, RJ: Vozes, 2010.

GATTT, Bernadete Angelina. Formação de professores no Brasil: características e problemas. In: Educação \& Sociedade, Campinas, v. 31, n. 113, 2010, p. 1355-1379.

GONÇALVES, Terezinha Valim Oliver. Formação De Professores De Ciência E Matemáticas Desafios Do Século XXI. Livraria Da Física. 2013.

KNELLER, George Frederick. Arte e ciência da criatividade. 14ª . Ed. São Paulo: Ibrasa. 1999.

MARANDINO, Martha; SELLES, Sandra Escovedo; FERREIRA, Marcia Serra. Ensino de Biologia: histórias e práticas em diferentes espaços educativos. São Paulo: Cortez, 2009. (Coleção Docência em Formação. Série Ensino Médio).

MARCELO GARCÍA, Carlos; VAILLANT, Denise. Desarrollo Profesional Docente: ¿Cómo se aprende a enseñar? Madrid: Narcea, 2009.

MIZUKAMI, Maria da Graa Nicoletti. et al. Escola e aprendiragem da docência: Processos de investigação e formação. São Carlos: EdUFSCar, 2010. 203.p

PILETTI, Nelson. Psicologia Educacional. $3^{a}$ ed. São Paulo: Ática, 1997.

ROCHA, Carlos José Trindade. Desenvolvimento profissional docente em perspectiva do ensino por investigação em um Clube de Ciências da UFPA. 2019. 185 f. Tese (Doutorado). Universidade Federal do Pará. Programa de Pós-Graduação em Educação em Ciências e Matemáticas. Belém. Pará.

ROCHA, Carlos José Trindade; MALHEIRO, João Manoel da Silva. Interações dialógicas na experimentação investigativa em um Clube de Ciências: proposição de instrumento de análise metacognitivo. Amaz RECM. Especial Metacognição, v. 14, n. 29, p. 193-207. 2018.

ROCHA, Carlos José Trindade; FARIAS, Sidilene Aquino. Metodologia Ativas de Aprendizagem possíveis em Ensino de Ciências e Matemáticas. Revista Reamec, v. 8, n. 2, p. 69-87, 2020. DOI: 10.26571/reamec, v8i2.9422.

ROCHA, Carlos José Trindade; MALHEIRO, João Manoel da Silva. Clube de ciências Prof. Dr. Cristovam Wanderlei Picanço. Diniz e o ensino investigativo no município de Castanhal-Pará. Anais... Encontro Nacional de Ensino de Ciências por Investigação. ENECI. Faculdade de Educação da USP - FE-USP. São Paulo. 2017.

ROSSI, Fernanda; HUNGER, Dagmar. As etapas da carreira docente e o processo de formação continuada de professores de Educação Física. Rev. bras. Educ. Fis. Esporte, São Paulo, v. 26, n. 2, 2012, p. 323-38. 
DOI: $10.12957 /$ teias.\%Y.50913

SILVA, Roberto Ribeiro da; MACHADO, Patrícia Fernandes Lootens; TUNES, Elizabeth. Experimentar Sem Medo de Errar. Cap. 9, p. 231-261. In: Ensino de Química em Foco. (org) SANTOS, Wildson e MALDANER, Otávio, Ed. Unijuí. 2010.

SIRY, Christina; KREMER, Isabelle. (2011). Children explain the rainbow: using young children's ideas to guide science curricula. Journal of Science Education and Technology, 20, p. 643-655. Disponível em https://doi.orgQ10.1007/s10956-011-9320-5. Acesso em abr. 2020.

STENGERS, Isabelle. Quem tem medo da ciência? ciência e poderes. São Paulo: Siciliano, 1990.

TARDIF, Maurice. A profissionalização do ensino passados trinta anos: dois passos para frente, três para trás. In: Educação \& Sociedade. Campinas, v.34, n. 123, 2013, p. 551- 571.

VAILLANT, Denise; MARCELO, Carlos. Ensinando a ensinar. As quatro etapas de uma aprendizagem/ Denise Vaillant, Carlos Marcelo. - 1. Ed. Curitiba: Ed. UFTPR, 2012.

Submetido em maio de 2020

Aprovado em novembro de 2020

\section{Informações do autor}

Carlos José Trindade da Rocha

Universidade Federal do Pará - UFPA/Programa de Pós-Graduação em Estudos Antrópicos na

Amazônia - PGEAA; Secretaria de Estado de Educação do Pará - SEDUC/PA.

E-mail: carlosjtr@hotmail.com

ORCID: https://orcid.org/0000-0001-5172-9182

Link Lattes: http://lattes.cnpq.br/7815926450187234 